Proceedings of the 2011 Winter Simulation Conference

S. Jain, R.R. Creasey, J. Himmelspach, K.P. White, and M. Fu, eds.

\title{
USING DISCRETE EVENT SIMULATION TO EVALUATE THE LOGISTICS OF MEDICAL ATTENTION DURING THE RELIEF OPERATIONS IN AN EARTHQUAKE IN BOGOTA
}

\author{
Diomar Noreña \\ Universidad de los Andes \\ Carrera 1a No. 18A-10 \\ Bogotá DC, A.A. 12340, COLOMBIA \\ Luis Yamín \\ Universidad de los Andes \\ Carrera 1a No. 18A-10 \\ Bogotá DC, A.A. 12340, COLOMBIA
}

\author{
Raha Akhavan-Tabatabaei \\ Universidad de los Andes \\ Carrera 1a No. 18A-10 \\ Bogotá DC, A.A. 12340, COLOMBIA
}

Wilfredo Ospina

Bogotá District Emergency Management Agency

Diagonal 47 No.77B-09 int11

Bogotá DC, COLOMBIA

\begin{abstract}
City of Bogotá the capital of Colombia, is located in a region with a high risk of natural disasters including earthquakes. Over the past few years the city officials have been developing high level emergency plans to cope with such disasters. However the current emergency plan lacks details on the logistics of medical attention. The motivation of this work is to evaluate the efficiency of the current emergency plan in attending the injured within the first four days of an earthquake. We present a simulation model to transfer the injured people to the temporary and permanent hospitals. The model takes into account the current capacity and occupation rate of the permanent hospitals, the current number of ambulances in the zone and the approximate duration of destructed routes among others. The model outcomes are used by the government agencies to reduce the uncertainty impact on planning the logistics of relief operations.
\end{abstract}

\section{INTRODUCTION}

International Federation of Red Cross and Red Crescent Societies (IFRC) define a disaster as "a sudden, calamitous event that seriously disrupts the functioning of a community or society and causes human, material and economic or environmental losses that exceed the community's or society's ability to cope using its own resources" (IFRC 2010). This definition reflects the urgent need in the society to correctly assess its existing resources and reduce the uncertainty impact of hazardous and disastrous situations on people's lives.

The seismicity, volcanic and other geological activities have constituted a significant hazard in most countries of Latin America (Costa et al. 2009). Therefore, in this region it is important to consider all possible actions in order to mitigate the negative impacts over their communities. Specifically, the problem of planning and preparation for the natural disasters has become crucial even more so since the economic losses caused by the natural disasters since 1940 demonstrate an increasing trend. Figure 1 shows the estimated cost of economic losses caused by natural disasters in Latin America and the Caribbean region.

Actions that can be taken by the Latin American governments correspond to the different stages of the disaster event, i.e., before, during and after the occurrence of the disaster. In the United States a comprehensive emergency management is commonly described in terms of four programmatic phases namely, mitigation, preparedness, response and recovery (Altay and Green 2005). Figure 2 shows the relation- 
ship between the three actual stages of a disaster, namely before, during and after and the four programmatic phases of emergency management.

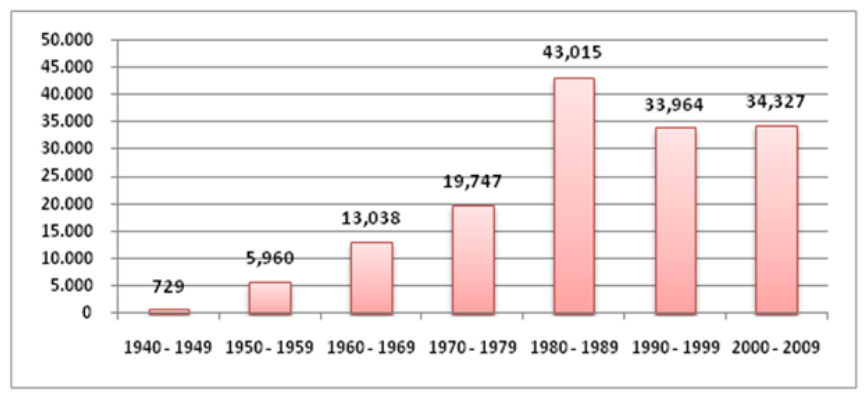

Figure 1: Estimated cost in 2009 US\$ million, EM-DAT. Bureau of Labor Statistics and IDB Staff Calculations, 2009.

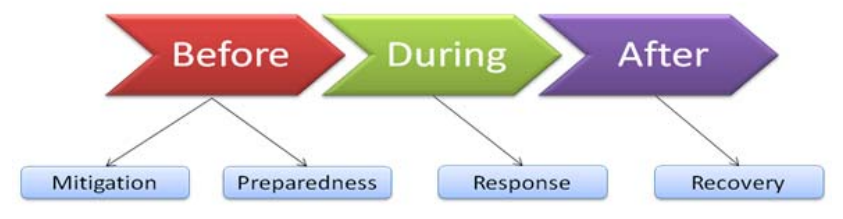

Figure 2: Relationship between programmatic phases and stages of disaster

In each one of these stages, the government institutions and NGO's have specific responsibilities to fulfill in accordance with the protocols made by corresponding disaster management institutions. In the case of Colombia and specifically its capital city Bogotá, the Prevention and Attention of Emergencies Fund (FOPAE) is the government institution in charge of the emergency management in all the stages of the disaster events.

Bogota's emergency plan (BEP) is focused on the occurrence of an earthquake taking into account the actual seismic risk in this region due to the fact that Bogota lies on a fault line. Also, BEP considers the potential danger that an earthquake poses to the city in terms of the disruption in the elementary services such as health, education and the daily activities of the citizens. Additionally, the risk is increased due to the housing conditions of the citizens because a fairly large portion of the population lives in informal settlements and slums which are not built to the correct safety regulations (Stone 2010).

In this study we focus on the preparedness and mitigation phases, considering the significant interest of the local government and the research that is done in this field. Table 1 shows the classification of the existing literature regarding Disaster Operations Management (DOM) (Altay and Green 2005). In this table we observe that problems regarding the preparedness and mitigation phases are the most commonly tackled by the researchers.

Our specific contribution in this study is concerning the behavior and functioning of the healthcare system, in the specific case where the injured and trapped people after an earthquake need to be transferred from the impacted locations to the permanent or temporary hospitals. Our motivation is to have a better understanding of the situation with the final goal of reducing the human losses.

We choose discrete event simulation as the tool to achieve this goal, since this OR technique allows a better understanding of that situation and is useful for the emergency planning at prevention and mitigation phases. Additionally, it is fairly easy to explain the components of a simulation model to nontechnical people who in this case are the customers of our research.

In the simulation model developed in this research we consider the currently available resources in each district including the number of permanent hospitals, ambulances, medicine, medical staff, hospital beds, pharmacies, etc. We also take into account information regarding the distances between different 
locations in each district, and also include in the model certain conditions caused by the disaster such as the possibility of not having the communications networks available.

Table 1: Statistics summary of articles on DOM (from Altay and Green (2005))

\begin{tabular}{|lccc|}
\hline Summary of statistics on DOM & & \\
\hline & All Journals & $\begin{array}{c}\text { OR related } \\
\text { outlets }\end{array}$ & $\begin{array}{c}\text { Main } \\
\text { stream OR } \\
\text { outlets }\end{array}$ \\
\hline Number of articles & 109 & 77 & 42 \\
\hline Authors nationality & $\%$ & $\%$ & $\%$ \\
\hline USA & 43.1 & 41.6 & 35.7 \\
\hline Othernations & 42.2 & 41.6 & 47.6 \\
\hline International & 14.7 & 16.8 & 16.7 \\
\hline Publication time & $\%$ & $\%$ & $\%$ \\
\hline 1980's & 12.8 & 13.0 & 19.0 \\
\hline 1990 s & 40.4 & 40.2 & 40.5 \\
\hline Since 2000 & 46.8 & 46.8 & 40.5 \\
\hline Operationalstage & $\%$ & $\%$ & $\%$ \\
\hline Mitigation & 44.0 & 48.1 & 45.2 \\
\hline Preparedness & 21.1 & 19.5 & 19.0 \\
\hline Response & 23.9 & 26.0 & 33.3 \\
\hline Recovery & 11.0 & 6.4 & 2.5 \\
\hline
\end{tabular}

The rest of this paper is organized as follows. In the following section we review the relevant literature on the application of OR tools and techniques in disaster operations management. A description of the problem statement that is considered in this research is given in Section 3. In Section 4 we explain the methodology used to tackle the problem, while Section 5 contains the results that we obtain from the simulation model on a number of sample cases and the analysis of these results. Finally we present the conclusions of the research and the future work in Section 6.

\section{LITERATURE REVIEW}

Different approaches and OR techniques have been proposed to study the large range of problems on DOM such as allocation of resources, humanitarian logistics and vehicle routing problems in disaster situations, among others. In this section we review relevant problems in different disaster phases that are tackled using different OR tools and solution methods.

Balcik and Beamon (2008) develop a variant of the maximal covering location model to determine the number and locations of distribution centers in a relief network, and the amount of relief supplies to be stocked at each distribution center. Fiedrich, Gehbauer, and Rickers (2000) also uses the methodology of math programming to tackle the problem of finding the best assignment of available resources to operational areas for different tasks related to the response phase.

Iannoni et al (2010) use an adapted hypercube approximation algorithm which is based on spatially distributed queuing theory, to address the decisions of location and districting associated with the design of large-scale ambulance operations on highways.

In the field of humanitarian logistics Van Wassenhove and Pedraza Martinez (2010) present two cases of OR applications to field vehicles fleet management which are used to transport staff, aid items and material. This problem is especially important in a disaster situation since transportation is the second largest overhead cost to humanitarian organizations after personnel.

Tang and Wen (2009) develop an intelligent simulation system that allows a quick evaluation of seismic losses after earthquakes and make an intelligent emergency response during the earthquake and post-earthquake. Through this system, seismic disaster mitigation strategies can be verified during a preearthquake stage, and be executed at the time of an earthquake and post-earthquake.

In this study we specifically tackle the problem of transportation of injured and trapped people to permanent and temporary hospitals. We choose discrete event simulation as the OR technique to approach this problem since we need to understand the interaction among all players in the situation such as injured 
and trapped people, ambulances, medical staff, etc. Through the simulation outcomes we attempt to understand the behavior of the healthcare system in a real situation and propose policies and strategies to reduce the number of victims in an earthquake disaster.

Simulation has been commonly used as one of the most popular OR tools in the field of DOM. Altay and Green (2006) classify the OR techniques used in DOM by frequency of appearance in journal articles. Table 2 shows that simulation is the third commonly used technique by researchers after math programming and probability and statistics.

Table 2: Methodologies used in articles on DOM

\begin{tabular}{|lccc|}
\hline Summarystatistics of articles on DOM & Alljournals & $\begin{array}{c}\text { OR related } \\
\text { outlets }\end{array}$ & $\begin{array}{c}\text { Main stream } \\
\text { OR outlets }\end{array}$ \\
\hline Number of articles & 109 & 77 & 42 \\
\hline Methodology & $\%$ & $\%$ & $\%$ \\
\hline Math programming & 32.1 & 36.4 & 42.9 \\
\hline $\begin{array}{l}\text { Probability and } \\
\text { statistics }\end{array}$ & 19.2 & 15.6 & 16.7 \\
\hline Simulation & 11.9 & 11.7 & 11.9 \\
\hline $\begin{array}{l}\text { Decision theory and } \\
\text { MAUT }\end{array}$ & 10.1 & 9.1 & 4.8 \\
\hline Queuing theory & 9.2 & 13.0 & 11.9 \\
\hline Fuzzy sets & 5.5 & 3.9 & 0.0 \\
\hline $\begin{array}{l}\text { Stochastic } \\
\text { programming }\end{array}$ & 3.7 & 5.2 & 4.8 \\
\hline Experts systems & 3.7 & 2.6 & 2.4 \\
\hline Systems Dynamics & 1.8 & 0.0 & 0.0 \\
\hline $\begin{array}{l}\text { Constraint } \\
\text { programming }\end{array}$ & 0.9 & 1.3 & 2.4 \\
\hline Soft OR & 0.9 & 1.3 & 2.4 \\
\hline
\end{tabular}

\section{PROBLEM STATEMENT}

In a disaster event such as an earthquake there are different types of needs in the population that have to be addressed by the government authorities and institutions to mitigate the impact of the calamitous emergency. One of the most urgent of such needs is to deliver immediate medical care to the victims of the disaster. In the context of an earthquake we can find different status of people depending on their conditions after the quake.

The people involved in a disaster can be roughly categorized as affected, injured or trapped, dead or unaffected. The affected people are those in need of food and shelter and possibly a minimum and outpatient medical attention. The injured and trapped people are those who have to be transferred to a medical facility for elaborate medical attention. The victims who have passed away during the event need to be transferred to a burial site. Depending on the severity of the disaster we can also find a population of unaffected people who have homes and food to live and can possibly offer help to the people in the first three categories.

In this study we focus on the category of injured and trapped people who have the need to be transported from the disaster area to permanent or temporary hospitals. To tackle the problem we select five districts of Bogotá with the highest vulnerability and population according to the damage scenario appendix from BEP (Pardo Torres and Escobar Castro 2007).

The districts are called Fontibon, Engativa, Kennedy, Teusaquillo and Puente Aranda which have residential and industrial structures but with different proportions. The damage scenario appendix states that Fontibon and Puente Aranda, are the districts with the highest vulnerability in the city in terms of the predicted number of injured and trapped people and destroyed area.

We first build a simulation model of the situation right after the occurrence of an earthquake with predefined characteristics. The city of Bogotá has changed dramatically since its last major earthquake many years ago. Therefore, historical information regarding the performance of the healthcare system in such a situation is scarce and much of the input data in the simulation model is estimated and approximated by the experts in the field. 
In this model we consider the distribution of injured people in the five districts and their lifetime depends on the level of injury, we also consider the population of trapped people because once they are helped by the rescue teams they can be categorized as the injured with high or low levels of injury. Additionally, we take into account that a proportion of the trapped people can be rescued too late and is classified as dead.

Using the above mentioned assumptions and input information we build a simulation model to represent the correct situation of the five districts in terms of attending the injured people after an earthquake with certain characteristics as considered in the BEP document (Pardo Torres and Escobar Castro 2007). Using the simulation model we examine the countermeasures predicted in the plan to cope with the disastrous situation in order to find the gaps between the required levels of aid operations and what is foreseen in the plan.

\section{METHODOLOGY}

The infrastructure and the housing conditions in the city of Bogotá result in high vulnerability in case of an earthquake with a high magnitude. The historical data shows that during the last three centuries, different earthquakes that occurred in 1785, 1827 and 1917 produced strong damage to the city's structures and infrastructure (Ojeda et al. 2002). This information motivates the government institutions and the population to create and design policies with the goal of improving the city's capacity to coordinate relief operations before, during and after an earthquake.

In the last two years the city has been particularly more active in developing prevention programs by activities such as carrying out annual evacuation drills and simulated disaster situations to measure the response performance for a potential earthquake. In 2010 the evacuation drill included nearly five million people between the government institutions, residential communities, shopping centers, schools, etc., (FOPAE 2010). This is approximately $68 \%$ of the total population in Bogotá.

\subsection{Bogota's Current Emergency Plan (BEP)}

The emergency prevention and attention department (FOPAE) is the Colombian government agency that is in charge of coordinating all institutions belonging to the local emergency prevention and attention system (SDPAE). FOPAE has the responsibility to design and define all the policies and instructions during the identification, prevention, mitigation and risk analysis stages of a disaster that are conducted by the different institutions.

As one of its main responsibilities FOPAE develops and updates the BEP for the entire city as a result of the joint work between specialists of different government institutions at local, regional and national levels. This plan considers among others, the general structure and the organizational control scheme during a disaster and also includes the general parameters and actions that the city, the institutions and the population have to implement in order to improve the response capacity in the city.

The BEP also includes a classification of all emergencies that can take place in the city such as floods, wildfires, landslides, earthquakes, etc. The frequently happening disasters such as floods and landslides are relatively easy to manage by FOPAE and the other emergencies institutions. However, earthquakes although not as frequent can be far more dangerous to the city given their high potential for destruction. For that reason the BEP is focused on the activities of mitigation and preparedness to face such situations.

The BEP is composed of a central document and twelve appendices. Among them there is an appendix that defines the damage scenario that the city prepares for. This document defines the specific characteristics of an earthquake such as the magnitude, epicenter and depth that are assumed by FOPAE in order to have a baseline with which the emergency department can make its plan.

The seismic source selected in damage scenario appendix (DSA) was the frontal fault on the Eastern mountains range, with a magnitude of 6.2 on the Richter scale, return period of 250 years, $23 \mathrm{Km}$ of deep 
and epicentral distance from the frontal fault of $39.5 \mathrm{Km}$. We take into account these characteristics in this study to develop the simulation model.

Another factor, the damage of buildings infrastructure, is taken into account into DSA. This factor is an important issue not just in terms of supporting all preparedness and mitigation activities, but also in future regulations that can be taken by governments and emergency agencies after the disaster. An example of this was the significant code change that the Japanese government made in 1981 after the Kobe earthquake. Table 3 shows the damage statistics from major earthquakes in the world and also shows the statistics of buildings before and after the code change in Japan (Otani 2000).

Table 3 Damage statistics of buildings from major earthquakes

\begin{tabular}{|l|c|c|c|c|}
\hline Earthquake, year & Operational damage & Heavy damage & Collapse & Total \\
\hline Mexico City, 1985 & $4,251(93.8 \%)$ & $194(4.3 \%)$ & $87(1.9 \%)$ & 4,532 \\
\hline Lazaro Cardenas, Mexico, 1985 & $137(83.5 \%)$ & $25(15.2 \%)$ & $2(1.2 \%)$ & 164 \\
\hline Baguio City, Philippines, 1990 & $138(76.2 \%)$ & $34(18.8 \%)$ & $9(5.0 \%)$ & 181 \\
\hline Erzincan City, Turkey, 1992 & $328(77.4 \%)$ & $68(16.8 \%)$ & $28(6.6 \%)$ & 424 \\
\hline Kobe (pre-1981 construction), 1995 & $1,186(79.4 \%)$ & $149(10.0 \%)$ & $158(10.6 \%)$ & 1,493 \\
\hline Kobe (post-1982 construction), 1995 & $1,733(94.0 \%)$ & $72(4.0 \%)$ & $38(2.1 \%)$ & 1,844 \\
\hline
\end{tabular}

Among other things, FOPAE has developed the DSA to estimate the number of injured and trapped people in case of an earthquake with the characteristics defined in the BEP (Pardo Torres and Escobar Castro 2007). In this research we directly use the outcomes of this appendix as an input into the model.

We choose as an input to the model the estimated number of trapped and injured people classified by zones within each district. Appendix A Table A-1a shows the information regarding the trapped and injured people by zone in each district, if the earthquake happens during the day. In this table the zones with the highest and lowest number of injured and trapped people are highlighted, and also we include the abbreviations to identify each zone in the simulation model.

\subsection{Assumptions}

The assumptions and conditions that are included in the simulation model are as follows:

- The earthquake happens during the day: the occupation rate of buildings varies during different periods and hence the estimated number of trapped and injured people is a function of the occurrence time.

- The earthquake does not occur during the flu season: the occupational rate of the hospitals during the flu season is around $120 \%$ whereas in normal conditions this rate is decreased to $95 \%$ approximately.

- Hospitals do not get damaged: this assumption is critical to the model and in BET is justified by the reinforcement operations carried out to the city's major hospitals and health clinics.

- We assume the initial distribution of ambulances: the department of healthcare and human services has a policy to cover different areas in the city with the ambulances and we assume the current bases for the ambulances.

- The ambulances can drive at $30 \mathrm{~km} / \mathrm{h}$ : this is the speed that we assume according to the disaster situation and the studies about the normal speed that the ambulances can have.

- Rescue teams are available to support the emergency: this assumption is made according to the predefined duties of the rescue teams described in the BEP.

- Communications are available 8 hours after the earthquake.

- Number of additional cars in each district: in addition to the ambulances we assume a number of cars that offer services to carry the injured.

- Ambulance capacity: ambulances and cars can transport only one person at a time.

- Lifetime distribution for people with high level of injury. 


\subsection{Simulation model}

We design the simulation model following a logic that can be replicated in each zone of the different districts. First we classify the injured people due to the different medical procedures, using the START algorithm described by Sztajnkrycer, Madsen, and Báez (2006). This algorithm categorizes individuals into four categories, based on physiological parameters and ambulatory status. However, unlike the START algorithm that assumes four different classifications for injured people for simplicity in this simulation model we use two possible statuses for the injured people namely, high or low levels of injury. This revised classification is done base on the Start algorithm as Table 4 shows.

Table 4: Classification of injured people

\begin{tabular}{|c|l|}
\hline Classification for simulation model & \multicolumn{1}{c|}{ Start algorithm } \\
\hline \multirow{3}{*}{ People with high level of injured (HLI) } & $\begin{array}{l}\text { Priority red: a patient who requires urgent medical and } \\
\text { surgical treatment. Stabilization and immediate transfer } \\
\text { to hospital nearest suitable. }\end{array}$ \\
\hline \multirow{3}{*}{ People with low level of injured (LLI) } & $\begin{array}{l}\text { Priority yellow: A patient who requires stabilization and } \\
\text { treatment in second priority. }\end{array}$ \\
\cline { 2 - 3 } & $\begin{array}{l}\text { Priority Green: A person who requires outpatient treat- } \\
\text { ment. }\end{array}$ \\
\cline { 2 - 3 } & $\begin{array}{l}\text { Priority black: Patients with fatal injuries or without the } \\
\text { possibility of life. }\end{array}$ \\
\hline
\end{tabular}

The simulation model is constructed such that each zone has its own logic and it can be connected with other zones inside or out of the same district through the exchange of resources and hospital capacity. Figure 3 shows the flow diagram of the entities and resources within the simulation model.

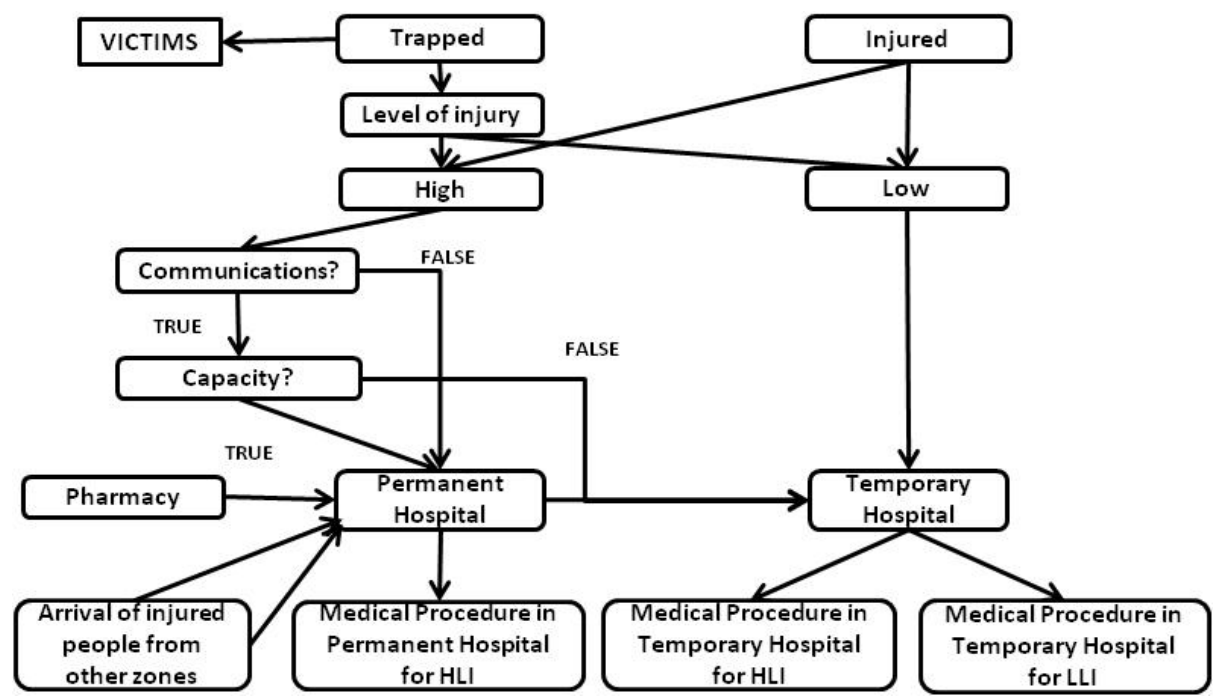

Figure 3: Logic of simulation model

In order to estimate the number of people with high and low levels of injury since no historical data is available in Colombia we use the estimated numbers from other countries that have sufficient data. Chen et al. (2009) in their study about trans-province transfer point out that "in Sichuan earthquake about 370,000 injured people had been rescued among them about 100,000 people needed inpatient care." Using such information in this paper we approximate the percentage of people with high level of injury as $27 \%$. The rest of the information that we include in simulation model comes from different sources. For 
example the number of pharmacies in each district comes from the information of the local municipalities and the information about the number of medical staff and beds in each hospital comes from the Department of Healthcare and Human Services. For undocumented information interviews are conducted with experts and city official and use their estimations in the model.

To include the information about the distances between the zones of this study, we use ArcGis software that lets us take into account the main and secondary routes within each district.

\subsection{Inputs}

The inputs that were used for the simulation model are the following:

- Number of trapped people

- Number of injured people

- Percent of trapped people dead

- Output rate for trapped people

- Percent of injured people with high level of injury (HLI)

- Communications available 8 hours after the earthquake

- Number of doctors, nurses and beds

- Amount of medicines for people with high and low level of injury in hospitals

- Number of hospitals and pharmacies

- Number of temporary hospitals

- Occupation rate for hospitals

- Number of ambulances in the districts

- Speed of ambulances

- Number of additional cars used for transportation of injured

- Duration of routes from disaster area to temporary and permanent hospitals

- Duration of medical procedures for people with high and low level of injury

- Time it takes for a supplier in supplying medicines to a hospital

- Lifetime for people with high level of injury

\section{RESULTS}

In this section we demonstrate results obtained from the simulation model with the input data and assumptions described in the previous sections. The total time of running for the simulation model is 96 hours, representing the first four days of immediate response after the earthquake. For each run of the model 30 replications are generated to provide statistical grounds for comparison.

In Table 5 we present the results of the simulation model for the five districts that are included in this study. In this table we present the results on the expected time that the injured people wait to be transported by an ambulance to a medical facility (request ambulance), also the time between arrival to the medical facility and when they are attended by the medical staff (medical procedure). The basic assumption in this table is that the city is using the free capacity of its permanent hospitals in the five districts as well as one temporary hospital with 15 beds and there is enough medical staff to attend the emergency in each zone of every district. However, we assume a total number of ambulances per district as shared resource among all the zones of the same district.

In Table 5 we observe that while the number of the ambulances available to attend the emergency increases the time of requesting ambulances decreases, and the waiting time to be attended in the permanent hospitals increases. It is also important to highlight that the waiting time for hospital in AME zone is zero when we have 30 ambulances because this hospital is the largest in terms of resources among all the facilities that are considered in this simulation model. 
Noreña, Akhavan-Tabatabaei, Yamin, and Ospina

Table 5: Waiting time for ambulance and medical attention with current hospital capacity

\begin{tabular}{|c|c|c|c|c|c|c|c|c|}
\hline \multicolumn{3}{|c|}{ Waiting time } & \multicolumn{2}{|c|}{30 ambulances } & \multicolumn{2}{|c|}{50 ambulances } & \multicolumn{2}{|c|}{100 ambulances } \\
\hline Item & District & Zone & Average (h) & Half width & Average (h) & Half width & Average (h) & Half width \\
\hline \multirow{10}{*}{$\begin{array}{l}\text { Request am- } \\
\text { bulance }\end{array}$} & \multirow{2}{*}{ Fontibon } & GT5 & 3.47 & 0.26 & 3.45 & 0.01 & 3.38 & 0.01 \\
\hline & & MOD6 & 0.03 & 0.07 & 0.05 & 0.08 & 0.00 & 0.00 \\
\hline & \multirow{2}{*}{ Engativa } & ALA & 3.35 & 0.02 & 3.26 & 0.03 & 2.74 & 0.04 \\
\hline & & JB & 0.07 & 0.05 & 0.04 & 0.11 & 0.02 & 0.09 \\
\hline & \multirow{2}{*}{ Kennedy } & CAR & 3.39 & 0.02 & 3.33 & 0.02 & 3.05 & 0.04 \\
\hline & & CAL & 0.00 & 0.00 & 0.00 & 0.00 & 0.00 & 0.00 \\
\hline & \multirow{2}{*}{ Teusaquillo } & TEU & 2.66 & 0.09 & 1.86 & 0.09 & 0.67 & 0.09 \\
\hline & & $\mathrm{LE}$ & 0.00 & 0.01 & 0.00 & 0.00 & 0.00 & 0.00 \\
\hline & \multirow{2}{*}{ P. Aranda } & $\mathrm{ZI}$ & 3.46 & 0.01 & 3.43 & 0.01 & 3.35 & 0.01 \\
\hline & & MZ & 0.15 & 0.12 & 0.02 & 0.04 & 0.02 & 0.06 \\
\hline \multirow{4}{*}{$\begin{array}{l}\text { Medical } \\
\text { attention }\end{array}$} & Fontibon & FONT & 0.36 & 0.01 & 0.66 & 0.02 & 1.32 & 0.03 \\
\hline & Kennedy & AME & 0.00 & 0.00 & 0.02 & 0.01 & 0.34 & 0.02 \\
\hline & Engativa & $\mathrm{BR}$ & 0.07 & 0.02 & 0.01 & 0.01 & 0.79 & 0.04 \\
\hline & Teusaquillo & TEU & 0.00 & 0.00 & 0.14 & 0.02 & 0.99 & 0.05 \\
\hline
\end{tabular}

Table 5 also shows the impact in waiting time when the number of ambulances is increased from 30 to 50 . In this case the expected waiting time to request an ambulance is decreased by $0.87 \%$ in the zone with the highest number of injured people from all districts (ZI). On the other hand, the expected waiting time is always 0.00 in the zone with the lowest number of injured people from all districts (CAL) because the estimated number of injured people is only one according to the damage scenario appendix (Pardo Torres and Escobar Castro 2007). In contrast, the waiting time to be attended in the hospital increases in all cases. For example in the permanent hospital of FONT this time increases by $83.33 \%$ due to the fact that the arrival rate of the injured to the hospital increases as the number of ambulances goes up. However, adding 50 more ambulances to the district decreases the expected waiting time to request an ambulance by $2.34 \%$ in ZI, while the expected waiting time to be attended in the hospital of FONT increases by $100 \%$.

The values given in Table 5 are considering the current resources that the city has planned for. However, as part of the analysis the city officials are interested in evaluating scenarios with temporary hospitals of smaller sizes. Appendix A Table A-1b shows the expected number of people that can be attended in temporary hospitals in each district with different scenarios for the size of the temporary hospitals. This table includes the results with varying number of ambulances. Also, it should be noted that each capacity has the abbreviation "CAP" to denote the number of resources available for a specific scenario.

Appendix B allows identifying effective policies regarding the size of the temporary hospitals and the number of ambulances. For example, in the case with 30 ambulances the appropriate number of beds is 5 as the resources for the temporary hospital in each zone of Fontibon. In this case although we increase the number of resources in the temporary hospital, since the transportation capacity by the ambulances is restricted we cannot increase the arrival rate of the patients to absorb the extra capacity in the hospital.

Analyzing the rest of the districts provides similar insight. For example, the suitable policy for Puente Aranda is to have 11 beds in each zone with 30 ambulances in the district. This behavior repeats in all of our cases where at a specific point the number of people attended by the temporary hospitals reaches the steady state. We can observe this behavior better in Figure 4 which includes all districts considered in the scenario with 30 ambulances.

Another important outcome of the simulation model is the number of fatalities with the current capacity that is available in the permanent hospitals. This information can be obtained based on the fact that the simulation model assumes a specific lifetime distribution for people with high level of injury. Figure B1a in Appendix B shows the estimated number of dead people with 30 ambulances considering the different scenarios for the capacity of the permanent hospitals. The extra capacity considered in the different scenarios is based on the current available capacity that we can find in the permanent hospital according to their occupational rate. 
Noreña, Akhavan-Tabatabaei, Yamin, and Ospina

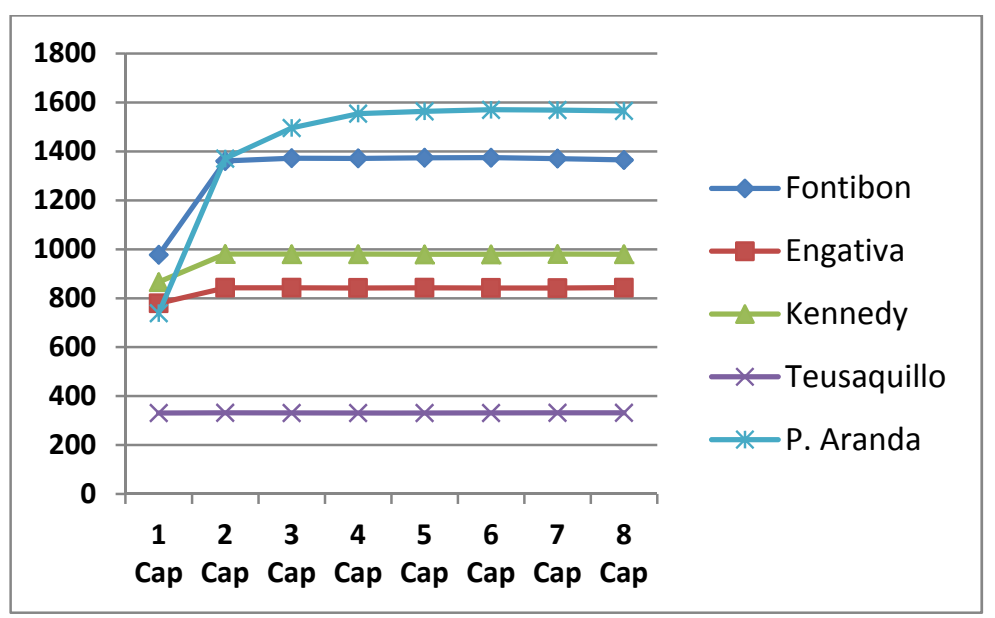

Figure 4: Number of people attended in temporary hospitals with 30 ambulances

The considered scenarios are relevant for the government agency in charge of disaster management (FOPAE), which has to analyze the situation in order to make the optimal policy, taking into account the available budget and aiming to achieve the minimum number of casualties. Figures B-1b and B-1c in Appendix B show the information with 50 and 100 ambulances respectively.

In this case, the main suggestion for the government authorities is to increase the resources (number of ambulances and the capacity of permanent hospitals) simultaneously and proportionately otherwise increasing one without changing the other will not have a significant impact on the number of fatalities. It is also important to evaluate the results according to their practicality in the real situation, because despite the fact that in Appendix B the number of fatalities in Figure B-1c is less than Figure B-1b hiring 100 ambulances in a disaster condition for zones with specific characteristics such as the traffic can be quite challenging.

\section{CONCLUSIONS}

In this research we construct a simulation model to evaluate the city's preparedness for attending the injured people after an earthquake with certain characteristics. The simulation model uses input information from the current emergency plan of Bogota (BEP) and evaluates a number of scenarios that are different in the number of available ambulances, the extra medical attention capacity provided for the disaster situation or both. The outcome of this model can be used to determine the appropriate capacity of the temporary medical facilities and ambulances for each district.

Results show that increasing the number of ambulances in a district is meaningful only if there is sufficient capacity for medical attention in the same district or in the neighboring districts. Otherwise the decision on the number of ambulances will not change the outcome in terms of number of fatalities. It is observed that when we increase the number of ambulances in each district we can improve only to some extent, the waiting time to request an ambulance and the number of people attended in temporary hospitals. However, it should be noted that an excessive number of ambulances could be counterproductive in practice during the disaster.

As the next step to complete this study we will consider extending the current model to all city districts and the possibility of receiving international aid. We will also take into account more details regarding the levels of injury and the type of medical care that the patients of each category will require. Also this model can be used as the base to solve the problem of locating optimal spots to set up the temporary hospitals. 


\section{A RESULTS FOR INJURED TRAPPED AND ATTENEDED PEOPLE}

Table A-1a: Estimated number of trapped and injured people by zone during the day

\begin{tabular}{|c|c|c|c|}
\hline District & Zone & Trapped & Injured \\
\hline \multirow{8}{*}{ Fontibon } & Fontibon (FONT) & 313 & 207 \\
\hline & Fontibon S.P. (FSP2) & 459 & 320 \\
\hline & Zona Franca (ZF3) & 247 & 173 \\
\hline & Ciudad Salitre Occidente (CSO4) & 73 & 37 \\
\hline & Granjas de Techo (GT5) & 2738 & 1904 \\
\hline & Modelia (MOD6) & 11 & 6 \\
\hline & Capellanía (CAP7) & 421 & 292 \\
\hline & Aeropuerto El Dorado (AED8) & 32 & 22 \\
\hline \multirow{9}{*}{ Engativa } & Las Ferias (LF) & 384 & 243 \\
\hline & Minuto de Dios (MD) & 163 & 90 \\
\hline & Boyacá Real (BR) & 247 & 157 \\
\hline & Santa Cecilia (SC) & 27 & 17 \\
\hline & Bolivia (BOL) & 215 & 117 \\
\hline & Garcés Navas (GN) & 56 & 36 \\
\hline & Engativa (ENG) & 126 & 86 \\
\hline & Jardin Botánico (JB) & 7 & 5 \\
\hline & Alamos (ALA) & 545 & 377 \\
\hline \multirow{12}{*}{ Kennedy } & Americas (AME) & 247 & 166 \\
\hline & Carvajal (CAR) & 598 & 402 \\
\hline & Castilla (CAS) & 280 & 186 \\
\hline & Kennedy Central (KC) & 100 & 55 \\
\hline & Timiza (TIM) & 154 & 84 \\
\hline & Tintal Norte $(\mathrm{TN})$ & 55 & 39 \\
\hline & Calandaima (CAL) & 1 & 0 \\
\hline & Corabastos (COR) & 93 & 64 \\
\hline & Gran Britalia (GB) & 55 & 36 \\
\hline & Patio Bonito (PB) & 12 & 8 \\
\hline & Las Margaritas (LM) & 0 & 0 \\
\hline & Bavaria (BAV) & 386 & 268 \\
\hline \multirow{6}{*}{ Teusaquillo } & Galerias (GAL) & 182 & 102 \\
\hline & Teusaquillo (TEU) & 342 & 182 \\
\hline & Parque Simon Bolivar (PSB) & 32 & 16 \\
\hline & La Esmeralda (LE) & 14 & 7 \\
\hline & Quinta Paredes (QP) & 230 & 128 \\
\hline & Ciudad Salitre Oriental (CSOR) & 23 & 14 \\
\hline \multirow{5}{*}{$\begin{array}{l}\text { Puente } \\
\text { Aranda }\end{array}$} & Ciudad Montes (CM) & 414 & 269 \\
\hline & Muzú (MZ) & 36 & 21 \\
\hline & San Rafael (SR) & 271 & 178 \\
\hline & Zona Industrial (ZI) & 2864 & 1948 \\
\hline & Puente Aranda (PA) & 1047 & 727 \\
\hline
\end{tabular}

Table A-1b: Expected number of people attended in temporary hospitals during four days

\begin{tabular}{|c|c|c|c|c|c|c|}
\hline Number & \multicolumn{3}{|c|}{1 CAP: 1 bed } & \multicolumn{3}{|c|}{2 CAP: 3 bed } \\
\hline Attended in TH & $30 \mathrm{amb}$ & $50 \mathrm{amb}$ & $100 \mathrm{amb}$ & $30 \mathrm{amb}$ & $50 \mathrm{amb}$ & $100 \mathrm{amb}$ \\
\hline Fontibon & $976.8 \pm 5.0$ & $956.5 \pm 6.5$ & $950.0 \pm 4.4$ & $1360.6 \pm 6.1$ & $1583.4 \pm 5.0$ & $1594 \pm 5.4$ \\
\hline Engativa & $778.8 \pm 5.6$ & $784.3 \pm 5.4$ & $771.0 \pm 9.2$ & $842.3 \pm 6.0$ & $854.5 \pm 7.7$ & $873.4 \pm 7.7$ \\
\hline Kennedy & $866.0 \pm 8.9$ & $909.8 \pm 6.5$ & $922.2 \pm 7.1$ & $980.2 \pm 6.5$ & $990.7 \pm 7.0$ & $1008 \pm 7.4$ \\
\hline Teusaquillo & $330.6 \pm 3.6$ & $330.3 \pm 3.5$ & $328.3 \pm 3.2$ & $331.2 \pm 3.6$ & $329.7 \pm 3.4$ & $329.4 \pm 3.2$ \\
\hline P. Aranda & $738.4 \pm 7.3$ & $749.26 \pm 5.0$ & $727.3 \pm 2.9$ & $1370.8 \pm 13.9$ & $1577.3 \pm 14.2$ & $1647.0 \pm 6.1$ \\
\hline Number of people & \multicolumn{3}{|c|}{3 CAP: 5 bed } & \multicolumn{3}{|c|}{4 CAP: 7 bed } \\
\hline Attend & $30 \mathrm{amb}$ & $50 \mathrm{amb}$ & $100 \mathrm{amb}$ & $30 \mathrm{amb}$ & $50 \mathrm{amb}$ & $100 \mathrm{amb}$ \\
\hline Fontibon & $1372.2 \pm 7.1$ & $1683.5 \pm 14.6$ & $2166.9 \pm 6.2$ & $1371.1 \pm 8.9$ & $1708.0 \pm 22.1$ & $2429.4 \pm 15.6$ \\
\hline Engat & $842.3 \pm 5.9$ & $854.7 \pm 7.6$ & $875.4 \pm 9.1$ & $841.5 \pm 5.9$ & $852.7 \pm 7.7$ & $878.7 \pm 8.6$ \\
\hline Kenr & $980.0 \pm 6.7$ & $990.0 \pm 7.1$ & $1007.5 \pm 7.3$ & $979.8 \pm 6.7$ & $990.6 \pm 7.1$ & $1006.6 \pm 7.4$ \\
\hline Teus: & $330.7 \pm 3.5$ & $330.4 \pm 3.4$ & $329.1 \pm 3.2$ & $330.9 \pm 3.7$ & $329.9 \pm 3.3$ & $329.4 \pm 3.3$ \\
\hline P. Ara & \multirow{2}{*}{\multicolumn{3}{|c|}{$\begin{array}{c}1496.2 \pm 11.0|1914.0 \pm 14.4| 2211.8 \pm 8.0 \\
\text { 5 CAP: } 9 \text { bed }\end{array}$}} & \multicolumn{3}{|c|}{\begin{tabular}{|l|l|l}
$1554.4 \pm 9.1$ & $2160.3 \pm 21.4$ & $2654.4 \pm 10.5$ \\
\end{tabular}} \\
\hline Number of people & & & & \multicolumn{3}{|c|}{6 CAP: 11 bed } \\
\hline Attende & $30 \mathrm{amb}$ & $50 \mathrm{amb}$ & $100 \mathrm{amb}$ & $30 \mathrm{amb}$ & $50 \mathrm{amb}$ & $100 \mathrm{amb}$ \\
\hline Fontibon & $1374.0 \pm 7.8$ & $1703.2 \pm 26.4$ & $2438.5 \pm 19$. & \multicolumn{3}{|c|}{\begin{tabular}{|l|l|l|}
$1374.3 \pm 10.0$ & $1708.2 \pm 26.4$ & $2444.1 \pm 26.8$ \\
\end{tabular}} \\
\hline Engat & $842.3 \pm 6.0$ & $853.6 \pm 7.8$ & $879.6 \pm 10.1$ & $841.3 \pm 6.0$ & $853.5 \pm 7.5$ & $875.4 \pm 7.7$ \\
\hline Kennedy & $979 \pm 6.7$ & $989.7 \pm 7.2$ & $1007.4 \pm 7.6$ & $979 \pm 6.8$ & $990.8 \pm 6.9$ & $1009.2 \pm 7.6$ \\
\hline Teusaqu & $330.8 \pm 3.7$ & $329.9 \pm 3.5$ & $329.3 \pm 3.2$ & $330.5 \pm 3.6$ & $330.1 \pm 3.4$ & $329.1 \pm 3.3$ \\
\hline P. Ar & $1563.8 \pm 10.1$ & $2379.9 \pm 19.9$ & 2723. & $1570.2 \pm 10.0$ & $2557.9 \pm 22$ & $2732.0 \pm 24.6$ \\
\hline Number of people & \multicolumn{3}{|c|}{7 CAP: 13 bed } & \multicolumn{3}{|c|}{8 CAP: 15 bed } \\
\hline Attended in TH & $30 \mathrm{amb}$ & $50 \mathrm{amb}$ & $100 \mathrm{amb}$ & $30 \mathrm{amb}$ & $50 \mathrm{amb}$ & $100 \mathrm{amb}$ \\
\hline Fontibon & $1370.5 \pm 7.6$ & $1698.9 \pm 26.4$ & $2453.6 \pm 23.9$ & $1365.1 \pm 8.2$ & $1702 \pm 28.7$ & $2431.8 \pm 17.2$ \\
\hline Engativa & $841.1 \pm 6.1$ & $854.2 \pm 7.5$ & $877.2 \pm 8.6$ & $842.7 \pm 6.0$ & $855.3 \pm 7.6$ & $876.6 \pm 8.2$ \\
\hline Kennedy & $980.2 \pm 6.7$ & $990.3 \pm 7.2$ & $1007.6 \pm 7.4$ & $979.7 \pm 6.7$ & $989.7 \pm 7.1$ & $1006.9 \pm 7.4$ \\
\hline Teus & $331.2 \pm 3.7$ & $330.2 \pm 3.5$ & $329.2 \pm 3.3$ & $331.3 \pm 3.7$ & $330.3 \pm 3.4$ & $329.0 \pm 3.3$ \\
\hline P. Aranda & $1569 \pm 11.2$ & $2559.4 \pm 16$ & $2735.7 \pm 2$ & $1565.3 \pm 10.2$ & $2556.9 \pm 19.0$ & $2720.2 \pm 14.4$ \\
\hline
\end{tabular}

\section{B NUMBER OF DEATHS WITH VARIOUS AMBULANCE SCENARIOS}

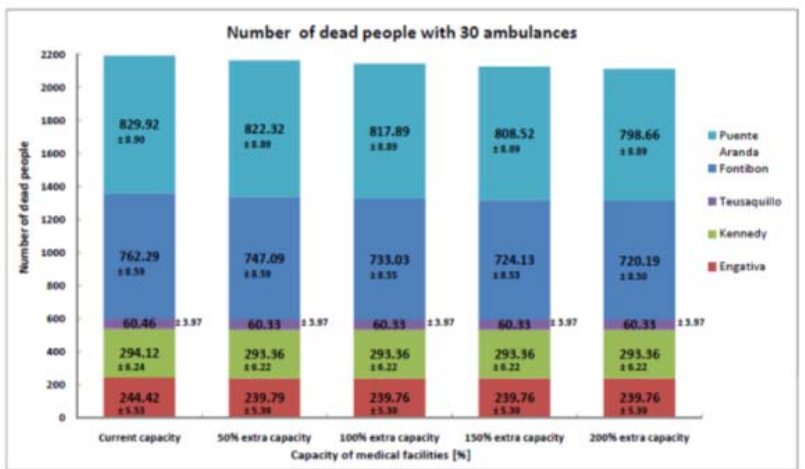

Figure B-1a: Number of deaths with 30 ambulances

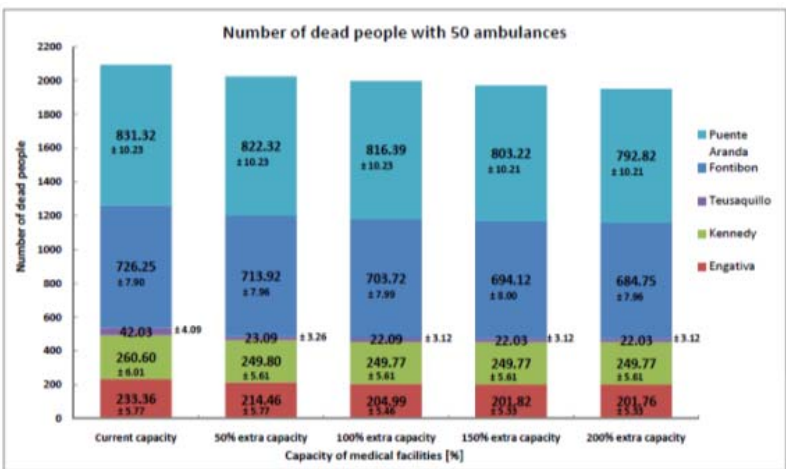

Figure B-1b: Number of deaths with 50 ambulances 
Noreña, Akhavan-Tabatabaei, Yamin, and Ospina

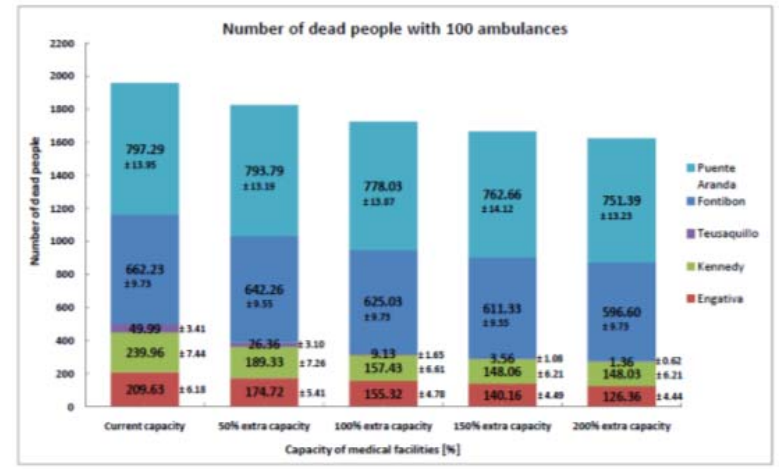

Figure B-1c: Number of deaths with 100 ambulances

\section{REFERENCES}

Altay, N., and W. G. Green. 2005. "OR/MS Research in Disaster Operations Management.” European Journal of Operational Research 175:475-493.

Balcik, B., and B. M. Beamon. 2008. "Facility Location in Humanitarian Relief." International Journal of Logistics: Research and Applications 11(2):101-121.

Chen, J., W. Zhao, M. Xian, J. Lu, and Z. Liang. 2009. "Trans-Province Transfer of 10,373 Patients Injured in Wenchuan Earthquake." Journal of Evidence-Based Medicine 2(4):270-276.

Costa, C. H., F. A. Audemard, L. Audin, and C. Benavente. 2009. "Geomorphology as a Tool for Analysis of Seismogenic Sources in Latin America and the Caribbean." Developments in Earth Surface Processes 13:29-47.

Fiedrich, F., F. Gehbauer, and U. Rickers. 2000. "Optimized Resource Allocation for Emergency Response after Earthquake Disasters." Safety Science 35(1-3):41-57.

FOPAE. 2010, January 25. Fondo de Prevencion y Atencion de Emergencias de Bogota. Accessed November 16, 2010. http://www.fopae.gov.co.

Iannoni, A. P., R. Morabito, and C. Saydam. 2010. "Optimizing Large Scale Emergency Medical System Operations on Highways.” Socio-Economic Planning Sciences 45(3):105-117.

IFRC. 2010, November 28. International Federation of Red Cross and Red Crescent Societies. Accessed November 28, 2010. http://www.ifrc.org.

Ojeda, A., S. Martinez, M. Bermudez, and K. Atakan. 2002. "The New Accelerograph Network for Santa Fe De Bogota, Colombia and Implications for Microzonation." Soil Dynamics and Earthquake Engineering 22(9-12):791-797.

Otani, S. 2000. "Seismic Vulnerability Assessment Methods for Buildings in Japan." Earthquake Engineering and Engineering Seismology 2(2):47-56.

Pardo Torres, J. A., and G. Escobar Castro, G. 2007, September. Sistema de Información de Riesgo y $\begin{array}{lllll}\text { Emergencias } & \text { (SIRE). } & \text { Accessed } & \text { January } & 29,\end{array}$ http://www.sire.gov.co/portal/page/portal/sire/manuales.

Stone, H. 2010, January 22. "Colombia Reports." Accessed January 25, 2010. http://colombiareports.com/colombia-news/news/7807-warnings-of-earthquake-risk-in-colombia.html

Sztajnkrycer, M. D., B. E. Madsen, and A. A. Báez. 2006. "Unstable Ethical Plateaus and Disaster Triage.” Emergency Medicine Clinics of North America 24(3):749-768.

Tang, A., and A. Wen. 2009. "An Intelligent Simulation System for Earthquake Disaster Assessment." Computers \& Geosciences 35(5):871-879.

Van Wassenhove, L. N., and A. J. Pedraza Martinez. 2010. "Using OR to Adapt Supply Chain Management Best Practices to Humanitarian Logistics." International Transactions in Operational Research (to appear). 


\section{AUTHOR BIOGRAPHIES}

DIOMAR NOREÑA is a former Master's student at the Department of Industrial Engineering, Los Andes University in Bogotá, Colombia. E-mail: dl.norena34@uniandes.edu.co.

RAHA AKHAVAN-TABATABAEI is an assistant professor at the Department of Industrial Engineering, Los Andes University in Bogotá, Colombia. She has received her master's and Ph.D. degrees in operations research and industrial engineering from Edward P. Fitts Department of Industrial and Systems Engineering, North Carolina State University, Raleigh, USA. E-mail: r.akhavan@uniandes.edu.co.

LUIS YAMÍN is an associate professor at the Department of Civil and Environmental Engineering, Los Andes University in Bogota, Colombia and CEO and partner Ingeniería Técnica y Científica Ltd. - ITEC Ltda, Bogotá, Colombia (Engineering consulting company) since 1995 acting as Structural Engineer and Project Leader in earthquake engineering, dynamics of structures, natural hazards and infrastructure risk evaluations and specialized software development for earthquake engineering and risk analysis. He is also International consultant for natural hazard and risk modeling with ERN-Colombia and ERN-Latin America for the World Bank, IDB - Inter American Development Bank and CEPAL, the Economic Commission for Latin America and the Caribbean - ECLAC. He holds a Master of Science Degree in Civil Engineering from Stanford University, Palo Alto, USA. E-mail: lyamin@uniandes.edu.co.

WILFREDO OSPINA is the director of logistics at Fund for Prevention and Attention of Emergencies (FOPAE) for City of Bogota. He holds a B.Sc. degree in industrial engineering from Los Andes University, Bogotá, Colombia. E-mail: wospina@fopae.gov.co. 